\title{
The Influence of Oil Prices on Stock Market Returns in Saudi Arabian Companies: The Implementation of Econometric Models
}

\author{
Khodor SHATILA 1
}

DOI: $10.24818 / \mathrm{mer} / 2021.12-10$

\begin{abstract}
The countries in the sample are of special importance, as they have different rates of growth, different important characteristics of the financial system and levels of stock market progress. The research looks on equity market growth and measures its foreign economic effect, not in terms of profitability to investors (not beyond the scope of our study), but in terms of progress relative to the scale of these economies and the capital expenditure fund needs of those countries.

The data used in this study were taken from GCC's monthly time series over the 2008-2018 period. Such factors are actual interest rates, global development level, commodity market returns on commodities and the true price of oil (in US dollars). Thomson Reuters DataStream, Bloomberg and OECD database gather data for this study. For this study, the actual interest rate was selected as this element illustrates market swings.

The Industrial Production Index has defined it since the overall energy consumption in an economy is calculated by the amount of products and services generated in the region.

The research implemented and econometric approach throughout addressing data from 2008 till 2018 which means 10 years to study the impact of oil prices, exchange rates and their impact on stock market, case Saudi Arabia.

The key results showed that the contemporary and postponed impacts on economic development in either capital market liquidity, as measured by turnover or economic change, as measured by the institutional efficiency index. The relationship predictor (investment / Turnover ratio) was seen for the Arab countries to have an important result from the robustness measure. Implementing the strategy of gross capital expenditure expansion and the turnover partnership will lead to a positive impact on the connection between country expenditure and stock market liquidity during the competitive growth model.
\end{abstract}

KEYWORDS: Oil Prices, Stock Markets, Exchange rates, interest rates, KSA

JEL CLASSIFICATION: $A 10, A 13, C 12$

\section{INTRODUCTION}

In fact, a conventional model of endogenous growth will contribute to higher risk -sharing by globally integrated capital markets - portfolio diversification - reducing savings and sluggish economic growth. More broadly, financial integration, or other financial development may have an effect on deposits, on deposits distribution, or on the marginal capital product (Zhu, 2016).

This mechanism has an intuitively theoretical interpretation. An equity exchange makes both risk expansion and risk pooling a greater probability. In comparison, a formal stock market

\footnotetext{
${ }^{1}$ Masters' in Business Administration, Sagesse University, Furn El Chebbak Baabda, 1003, Lebanon; ORCID 0000-00021580-121X, shatilakhodor@gmail.com
} 
substantially improves knowledge for investors about corporations and their planned investment ventures. The outcomes are both more productive and the marginal capital product can thus be increased (Ramos, 2010).

Taking into account contradictory theory on how well-functioning stock markets are critical for economic growth, this analysis explores the effects on economic growth both of stock market production and change. It defines and addresses the key functions and quantitative metrics of the financial market within the economy, including market size by market capitalists, market operation by volume exchange and the turnover ratio for stock markets liquidity.

This research measures the significance of the production of the stock and economic change in economic growth for Arab countries by using sophisticated econometric techniques on panel data sets for these three categories, and the whole sample of 28 countries over the period 1980-2002, in the methodological sense and analysis of a research for and G-7 economies.

The countries in the sample are of special importance, as they have different rates of growth, different important characteristics of the financial system and levels of stock market progress. The research looks on equity market growth and measures its foreign economic effect, not in terms of profitability to investors (not beyond the scope of our study), but in terms of progress relative to the scale of these economies and the capital expenditure fund needs of those countries.

A contrast of Arab capital markets with the numerous Eastern Asia-Pacific financial structures and G7 markets in these countries has not been generally or ever implemented. Nevertheless, there are very few empirical examples of the value for economic growth of stock market production, almost none of which exist for Arab countries. The research involves 11 Arab countries with capital markets: Bahrain, Arabia Saudi, Tunisia, Egypt, Jordan, Kuwait, Lebanon, Morocco, Oman and Qatar.

The key findings of our research are, first of all, the absence of openness and liquidity concerns that limit the performance of these markets in the economy that have no major impact on economic development in Arab capital markets.

Our study's key challenge was to integrate various aspects of research across three different classes of countries. With rapid development and migration of the Arab capital markets as an alternate method to bank financing for private sector financing and development projects in the regional economy, this thesis has quickly developed. It took into account during the 19802002 era and its effects on economic development the recent economic and structural changes in Arab States. Although equity markets in Arab countries have operating formally and informally since the 1970's, accurate and clear estimates 5 on the size and development of these markets have been difficult to locate until very recently.

In the Arab financial markets, the study has been carried out on average. Lack of evidence restricts our analytical study of co-integration approaches and Granger-causality tests, as well as our capacity to analyze how economic growth follows financial progress. 
The view is recognized as the pursuit of demand; strong economic growth may generate requirements for some financial instruments and structures, and those demands and adjustments are effectively met by financial markets.

The evolving influences in recent years have been the increasing international participation in developing capital markets, the shift in Arab governments to open up their financial markets for foreign investors and the general propensity to control these markets safely. These improvements also culminated in improved data usability.

The International Financial Corporation (IFC) included most Arab stock markets and began building and publishing main market size and activities indicators in the region. The analytical work does not necessarily discuss the impact of financial development; it does not discuss variables such as monetary availability, banking reserves and domestic loans to private and public sectors

While various studies have studied the effect on economic growth of stock market creation, most centered on advanced economies and some centered on developing economies beyond Arab countries. Established economic analysis indicates that production of the equity market leads to economic growth. This thesis explores the position of the capital markets in Arab countries as they play an important role in investing and corporate finance.

\section{LITERATURE REVIEW}

\section{Volatility in Oil Prices and its impact on Stock Returns}

Many analysts have often been interested by the relationship between oil price fluctuation and stock market returns in GCC countries. In effect, numerous experiments to assess the relationship and its effects have been undertaken.

Momani (2012), in short-term use of linear and nonlinear regression model, investigate how oil price variations affect the bourse return of GCC countries (Bahrain, Kuwait, Saudi Arabia, Oman, Qatar and the UAE). They used weekly data for the duration between 7 June 2005 and 21 October 2008 in both versions. In order to obtain statistics on the weekly brent spot price of crude, the MSCI stock index was used to obtain details on market return volatility; and the Energy Information Administration (EIA). He used the linear regression model dependent on two variables: weekly brent oil price and weekly returns on each of the six nations. The linear regression model implemented by the study results ensure that the two variables in Oman, Qatar and UAE are directly related. In Bahrain, Kuwait and Saudi Arabia there are no connections. For countries whose economy relies on oil such as Saudi Arabia, this finding is counterintuitive.

Saudi Arabia has more fascinating conclusions, as Saudi Arabia has a negative relationship in the first regime, but a positive correlation in the second regime on a weekly basis. That means that the relationship is not linear and that there is an indication of improvements to the relationship depending on the amount of oil prices. Finally, Moghadam (2010) concludes that stock market relations in Qatar, Oman, Saudi Arabia and the UAE are strongly linked to the changes in oil prices in a nonlinear way and are shifted on an oil-price basis. In Bahrain and Kuwait, both models demonstrate that there are no effects on stock returns due to oil price volatility. 
Different empirical analyses have investigated the connection between oil prices and the macroeconomic factors such as GDP, growth, employment and exchange rates. Hamilton's US analysis on the connection between petroleum price and current GDP reveals that the impact of rising petroleum prices on real GDP is negative. This finding has been confirmed by a number of other researchers.

Various research subsequently examined the relationship between oil prices and financial markets. The study of Masih (2010) was one of the first academic studies to investigate the reactions of four developing nations, in the United States, Canada, Japan and Great Britain, to fluctuations in oil prices in international capital markets.

They also found that oil prices have a harmful effect on inventory returns for both of these countries using simple models of regression. In his study in the United States, Gomes (2014) drew the same conclusion. Dogan (2016) used the VAR approach to assess the effects of petroleum prices on the United States and thirteen European oil importing and exporting nations: for stock yield.

Empirical evidence shows the answer to the change from the equity market to oil as follows: in the case of oil exporting nations; a highly positive reaction in Norway; a significantly negative impact in the UK, while for the countries consuming oil the outcome was strongly negative.

The study shows that stocks of petroleum products affect portfolio returns asymmetrically. As a consequence of oil demand growth, equity market shares are the more than they are falling. The results have been supported by the study by Moghadam (2010), in which the asymmetric impact of oil price shocks on stock repayment is studied by GARCH's multivariate methodology.

Diaz (2016) study on China a certain path has been taken. They also employed a quantitative approach to address the effect of oil price shocks on China's stock returns. The connection in the experiments is asymmetrical. Oil supply and demand shock significantly reduces stock yields while combined demand shock improves stock returns after the bubble.

Dhaoui (2014) performed the six GCC countries nation test and just four GCC industries test (Bahrain, Kuwait, Oman, and Qatar). He have estimated, however, that just 11 out of 20 sectors have a substantial positive effect. (Bahrain: 1/6 - 3/7 Kuwait - Oman 4/4). The shared sector of commercial banks between the four countries demonstrates that the changes in oil prices (increase or decrease) and the returns from the business have a strong association. The commercial banking industry is an essential part of the stock market and GCC countries' economic system, which seemingly agreed. The effect on the industry depends largely on the preference of changing the market for customer care.

\section{Oil Prices and Stock returns in Emerging GCC Countries}

Panel analysis is another method used by Al-Qudah (2014) to research the long-term connection between oil prices and bond returns between emerging markets (GCC Countries). The relevance of this correlation has been stressed.

First of all, in the global energy sector, GCC countries are regarded as the main producers of gasoline. Secondly, GCC countries are too vulnerable to foreign policy activities as opposed 
to multinational countries. These countries are also seen as attractive places for the diversification of foreign portfolios.

The scale of the GCC financial sector was recorded by Al-Majali (2014) in terms of company numbers, market capitalisation, market turnover, and the proportion of petroleum revenue from GDP. Their strategy is founded on a stock price principle, in which the stock value is considered to be the amount of potential cash flows reduced by a certain discount rate. The price movements and demand volatility of oil will affect these discounted cash flows.

They used some recent techniques for the joint incorporation of the boot strap panel to research long-term relationships, and they used apparently unrelated regression (SUR) approaches to obtain the results for each region.

The monthly data from the Arab Monetary Fund (AMF) for the four countries was analyzed from January 1996 to December 2007. (Bahrain, Qatar, Oman, and Saudi Arabia). Newly created UAE and Qatar stock exchanges, which once founded in 2002 did not engage in the AMF database. They have used monthly OPEC spot pricing for oil prices.

As for the process, the bootstrap panel root unit analysis was used, with the basic Pesaran test and the computation of statistics on cross-sectional dependency. "This test bases on the standard increased Dickey-Fuller regressions for each human, average pair wise correlation coefficient of OLS residues received."

The zero hypothesis was that sectional freedom was still denied at 5\%, which confirms the cross sectional association in GCC countries. For the integration degree analysis, they applied Emith et al's bootstrap test, which was called a residual test, since only two series are usable and there are some data limitations. The findings of the panel's co-integrations revealed that oil prices and stock rates had long-term relationships with GCC four nations.

In the long term, however, oil markets and stock prices have shifted proportionally, as GCC stock exchange forces are still shifting oil prices. OPEC interference policies, international and domestic politics and economic activities, for example.

The other aspect of the report was to study the impact on each particular nation on the use of SUR figures. The findings seemed identical in the three nations, with the exception of Saudi Arabia, where they found that the long-term relationship mentioned earlier was quite inconsistent.

These changes are mostly attributed to lack of diversification and a strong degree of sensitivity for US and European financial markets, according to Al-Assaf (2014). Moreover, there are still vast numbers of listed enterprises in Saudi governments that they barely exchange.

Finally, they concluded that there were still gaps, considering the various general features of the GCC stock market. These differences should be considered by investors to conduct better portfolio management, and to be aware of the different potential yields available in each country.

The dynamic returns and transmission of uncertainty over capitalistic markets in GCC in relation to international prices is explored by Ajmi (2014). They split the time into regular 
times and periods of crisis, and during these two phases they analysed the six GCC countries. Furthermore, they used the modules for improved fund control to further hedging techniques (Hedge ratios for oil stock portfolio holdings).

The research carried out covers the 2005-2010 timeframe, the 2008 period prior to the United States crisis is called the usual era and the post-May 2008 phase is considered as crisis-one.

The VAR-GARCH technique is being implemented in Ajmi (2014). The complexities of this module are to research the uncertainty and the conditional side effects of interdependence. They used the results to determine the optimum weights and hedge ratios of the oil stocks portfolio.

The modules were focused on regular data for the six GCC Member States from 7 June 2005 to 21 February 2010. The global Brent oil prices were collected by the Energy Information Authority (EIA) and bond indices from the MSCI database were obtained.

According to the report, the module shows that the bond-market conditions vary depending only on its own innovative pasts and products, as well as on those of the oil market. This function therefore allows the clear passage from one sector to another of fluctuations and shocks."

The module effects can be synthesized as follows:

In a lagged sequence, stock valuation reveals a major explaining connection over the course of the whole time (only Bahrain and Qatar).

In all periods of crises (Normal and Crises) where there are strong elasticity in Qatar, oil prices are affected by financial markets in Bahrain, Oman and Qatar.

In Kuwait, Saudi Arabi and UAE, there have been no shock spillovers from oil during this entire time.

The effect of energy prices on the bond sector is more important and pronounced throughout the crisis time than the usual one.

\section{Saudi Arabia}

The Arabian Peninsula is home to Saudi Arabia, and the Kingdom was founded in 1932. He is also a part of the Islamic Cooperation Group, the GCC and OPEC. Its GDP in 2015 is USD 646 billion and its development rate is 3,5 percent. There are two thirds between agriculture, manufacturing and the utilities, $46 \%$ to $52 \%$ of the GDP.

Saudi Arabia is an oil exporter, its oil exports grew significantly between 1989 and 1991 and, in 2012, its oil exports increased to 7.7 million barrels a day accompanied by a small fluctuation with a general optimistic pattern. In the meantime, following a drastic decline from 1980 to 1985, oil production raised its pace and quantity up to about 9.7 million barrels a day in 2014, exceeding the same amount in about 1980.

In the span time from June 7, 2005, to May 25, 2010 with weekly results, Arouri and Rault (2010) investigated the correlation of GCC oil prices with stock prices. Throughout the Vector Auto Regression (VAR) test, researchers used panel data for the causality method of Granger. It indicates that Saudi Arabia is bidirectional to Granger from stock prices to oil prices. This is expected because KSA is the biggest oil exporter. Petroleum prices have a favorable correlation with government and industry revenues. A negative correlation had been 
recorded between the demand and equity markets, as the stock market in Saudi Arabia is shallower than any other, centralized and financially regulated.

Throughout the duration 2009 to 2012, the VAR-BEKK multivariate GARCH method was used daily for the analysis of the volatility impact and conditional correlation in the context of crude, stock exchange, and stock indices for various sectors in Saudi Arabia. The findings suggest a negative volatility in crude oil on the stock, while Jouini (2013) analyzed VAR GARCH methodology in the interaction of Saudi Arabia's stock market with the foreign oil price. Their evidence showed that there were negative relationship and volatility effects on oil prices on the stock market. The findings reveal that uncertainty varies and returns between stock and oil markets, whereas the energy spillover goes from oil market to other industries.

GARCH is used on the regular data by Dhaoui (2014) to research the effect of oil price fluctuations on the Saudi Arabia stock market from 2008 to 2012 using daily data. It implies exponential and constructive changes in Saudi oil markets, but the reverse is possible if the model contains more variables.

Diaz (2016) analyzed, by using monthly estimates in the GARCH DCC System for the period August 31, 2000 to June 31, 2010, four countries including Saudi Arabia, by using timevariable correlation coefficients. The competitive conditional link between financial markets and petroleum prices is positive and important, suggesting an increase of equity and oil price volatility. Throughout the duration 2000-2004 there has been a decline in the positive association as a result of the war on Iraq. The report showed that oil price fluctuations are triggered by global political factors.

In the period between 24 June 2005 and 25 March 2011, Gomes (2014) used weekly data to analyze the effects of the inventory in Saudi Arabia. Another interesting result is that the variability in the background had a larger function to play in forecasting present variability than in the background. Furthermore, the findings demonstrate bidirectional causality in conditions of heterogeneity between the two industries.

\section{METHODOLOGY}

The data used in this study were taken from GCC's monthly time series over the 2008-2018 period. Such factors are actual interest rates, global development level, commodity market returns on commodities and the true price of oil (in US dollars). Thomson Reuters DataStream, Bloomberg and OECD database gather data for this study. For this study, the actual interest rate was selected as this element illustrates market swings.

The Industrial Production Index has defined it since the overall energy consumption in an economy is calculated by the amount of products and services generated in the region.

\section{Regressions}

Multiple regressions were carried out to assess if the proposed theories may be accurate or not. Data have been included in this study group. Through the usage of table data it will be feasible either to run a pooled regression or to apply defined or changed results to the pooled regression if unknown variability is observed over time to a question to minimize the issue. Dummy variables are applied to the equation for period or cross-section results by utilizing fixed effects.

The stock market return is considered as a dependent variable for the initial regression, which attempts to analyze the general association between stock price output and oil price volatility. 
The original regression then looks like this:

Stock Returns $=\mathrm{A}+\mathrm{B}$ Oil Prices $+\mathrm{B}$ Exchange Rate $+\mathrm{B}$ Interest Rate $+\mathrm{B}$ Government Spending on Consumer + B Foreign Direct Investment + B Foreign Ownership Limit

Reasonable variables and interaction parameters were applied to the regressions in order to decide whether the association between stock returns and oil price volatility differed across various regional areas and parts. The word "interaction" indicates the interplay between two factors and results in a combination of both.

\section{VAR}

Value at risk (VaR) is a statistic that measures and quantifies the level of financial risk within a firm, portfolio or position over a specific period. This metric is most commonly used by investment to determine the extent and occurrence ratio of potential losses in their institutional portfolios.

VaR modeling determines the potential for loss in the entity being assessed and the probability of occurrence for the defined loss. One measures VaR by assessing the amount of potential loss, the probability of occurrence for the amount of loss, and the timeframe.

\section{FINDINGS}

\section{Market Return Trend from 2008 to 2018}

The below figure presents the market return trend from 2008 to 2018 in KSA in which it showed a mean of 7,334, a median of 7034, a maximum of 11486 and minimum of 4130, a standard deviation of 1366 and Skewness: and Kurtosis of 0.59 and 2.98 respectively.

However, and referring to the mentioned graph, it can be noticed that in 2008 there had been a high decline in the market returns from 10,000 reaching 4500 in 2009 and then it had showed a fluctuated increase reaching 6800 in 2010 and then decreasing to reach 5000 in 2011. Its peak was in the year of 2014 in which the market returns reached 11,000.

Below, in Figure 1 can be observed the descriptive analysis and the chart related to market return before making the transformation for the stationary reasons.

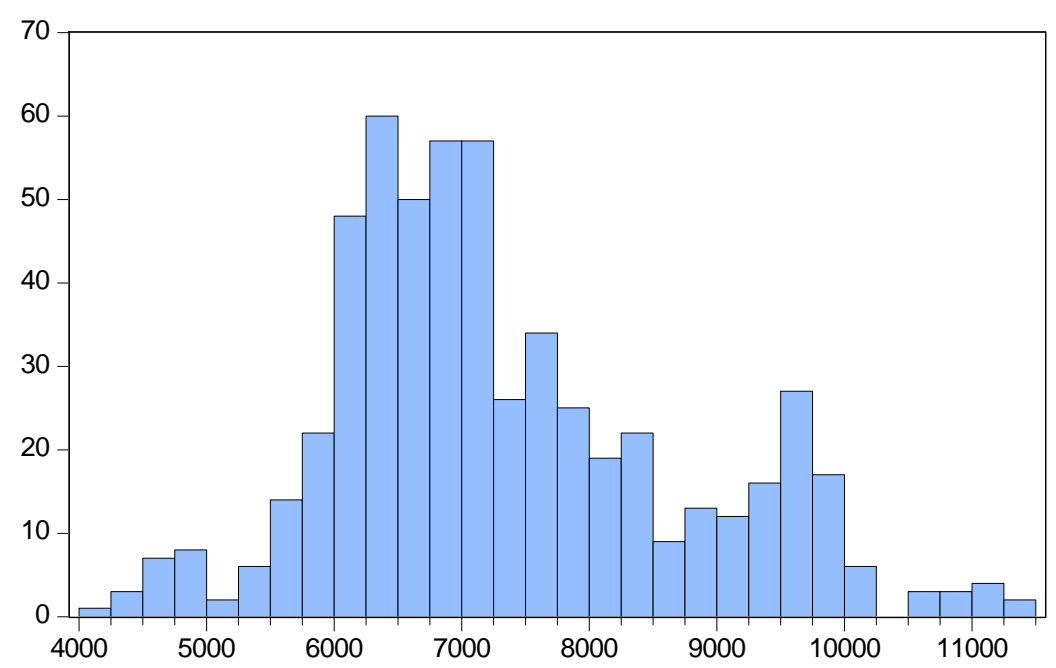

Series: MARKET_RETURN

Sample 1/11/2008 12/28/2018

Observations 573

Mean $\quad 7334.480$

Median $\quad 7034.080$

Maximum $\quad 11486.84$

Minimum $\quad 4130.150$

Std. Dev. $\quad 1366.384$

Skewness $\quad 0.594828$

Kurtosis $\quad 2.983381$

Jarque-Bera $\quad 33.79648$

Probability $\quad 0.000000$

Figure 1. Market return trend before the transformation for the stationary reasons Source: author's computation 
Secondly, in Figure 2 can be noticed that the minimum market returns was 4130 which had been observed in 2009 and the maximum market returns of 11486 had been observed in 2011 .

Market Return

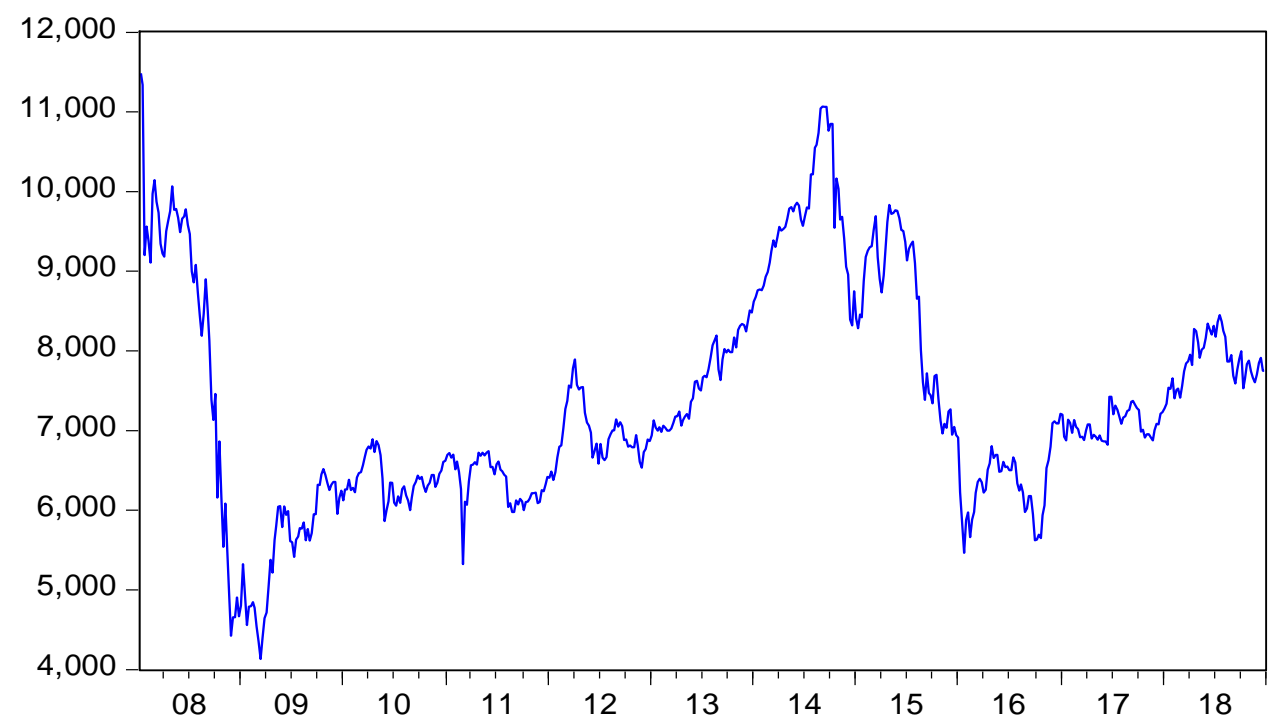

Figure 2. Market return. Graphic representation

Source: author's computation

Since we are dealing with a time serious data, then a stationary test is very critical to our module and to our analysis. A transformation should be made to the series by considering the change between the two periods instead of the value of figures itself. This transformation will enhance our module and increase the $\mathrm{R}$ squared and make the module more reliable. The data are presented in Figure 3.

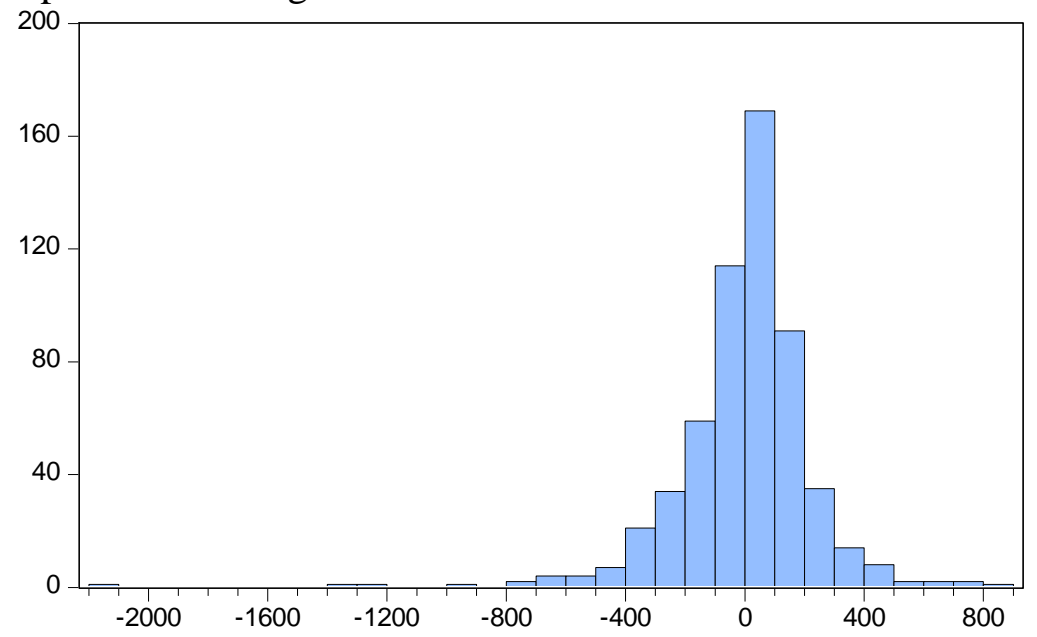

Series: D_MARKET_RETUNR

Sample 1/11/2008 12/28/2018

Observations 573

Mean $\quad-6.522723$

Median $\quad 11.78000$

Maximum $\quad 865.3200$

Minimum $\quad-2135.080$

Std. Dev. 232.7974

Skewness $\quad-2.077855$

Kurtosis $\quad 18.82597$

Jarque-Bera $\quad 6392.086$

Probability $\quad 0.000000$

Figure 3. Market return trend after the transformation for the stationary reasons Source: author's computation

\section{Brent Oil Prices Trend from 2008 to 2018}

The following graphs study the brent oil prices trend ranging from 2008 to 2018. However, it can be noticed that the brent oil trends had a mean of 81.59 , a median of 77.59 , a maximum of 144.4 and a minimum of 28.9 , a standard deviation of 26.86 . 
Referring to the trend analysis, it can be noticed that there had been a noticed increase in 2008 ranging from 85 to reach 140 and then dropped significantly to reach 40 in the mid of 2008 which is during the economic world crisis. It can be noticed that between the years 2009 and 2014 the brent oil had been fluctuating between 40 and 110. Then it decreased in the mid of 2015 to reach 25 scoring the lowest price. It can be observed in Figure 4 that the oil trend had scored a maximum price in 2008 scoring 144 and scored the lowest price in 2015 scoring 28.9 .

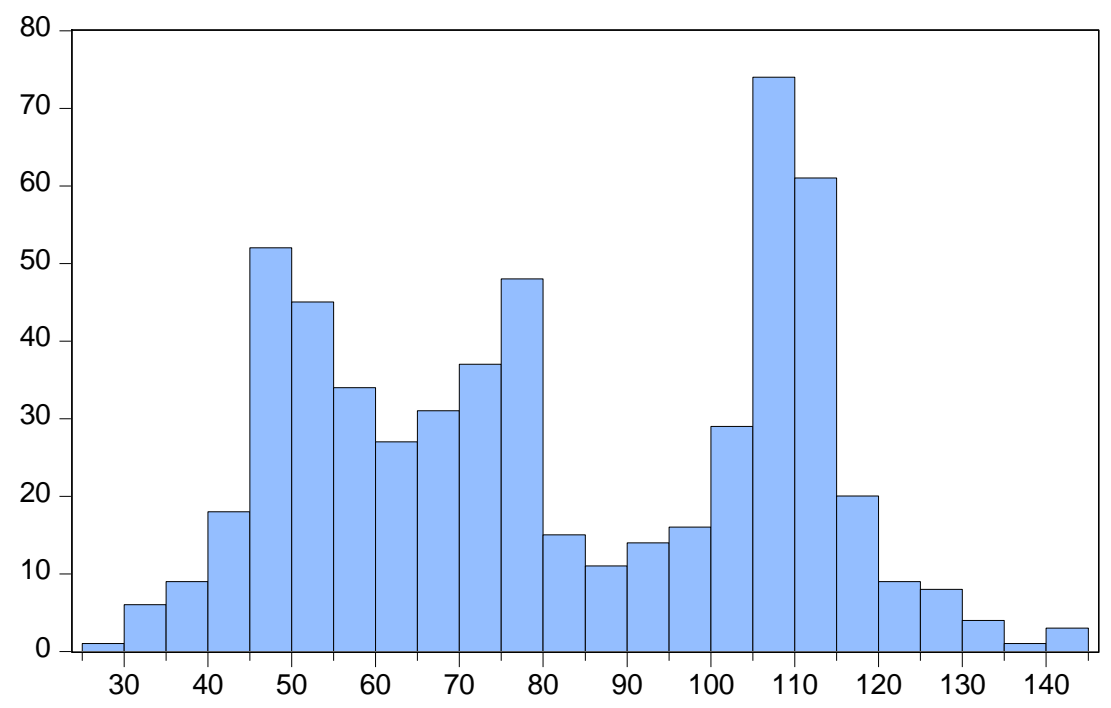

Series: OIL_PRICES _ BRENT Sample 1/11/2008 12/28/2018 Observations 573

Mean

81.59815

Median $\quad 77.59000$

Maximum $\quad 144.4900$

Minimum $\quad 28.94000$

Std. Dev. $\quad 26.86491$

Skewness $\quad 0.061667$

Kurtosis $\quad 1.706129$

Jarque-Bera $\quad 40.33234$

Probability $\quad 0.000000$

Figure 4. Oil prices trend

Source: author's computation

As mentioned before, the normality test is very critical for our regression and VAR module. An especially for the market return the Brent oil prices which are the main 2 variables in our paper. Since we are dealing with a time series data a transformation for this series should be done to be used in the module. The price itself is not the important for the analysis, but the change in the price between period $n$ and period $n-1$ is what add value to our module. In this case we should make a transformation for the series by creating the $\mathrm{D}$ series of the dependent variable (Change): D (Brent price) $=$ Brent Price- Brent Price $(-1)$ and use this new serious.

Figure 5 presents the histogram and descriptive data analysis related to the new series created (D- Oil prices). 


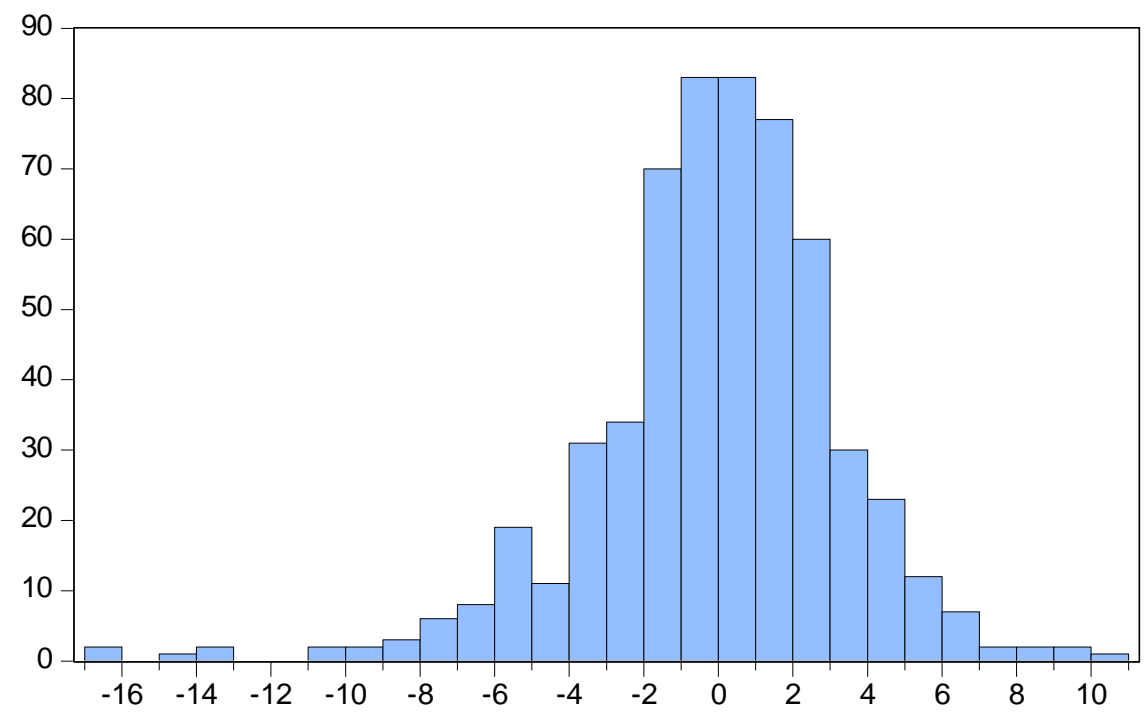

Series: D_OIL_PRICES

Sample 1/11/2008 12/28/2018

Observations 573

Mean

$-0.067836$

Median

0.130000

Maximum

10.84000

Minimum

$-16.76000$

Std. Dev.

3.391575

Skewness

$-0.807937$

Kurtosis

6.077633

Jarque-Bera $\quad 288.4786$

Probability

0.000000

Figure 5. Oil prices trend

Source: author's computation

In addition, Figure 6 presents the graphic representation for the oil prices.

\section{Oil Prices Chart}

Oil Prices ( Brent)

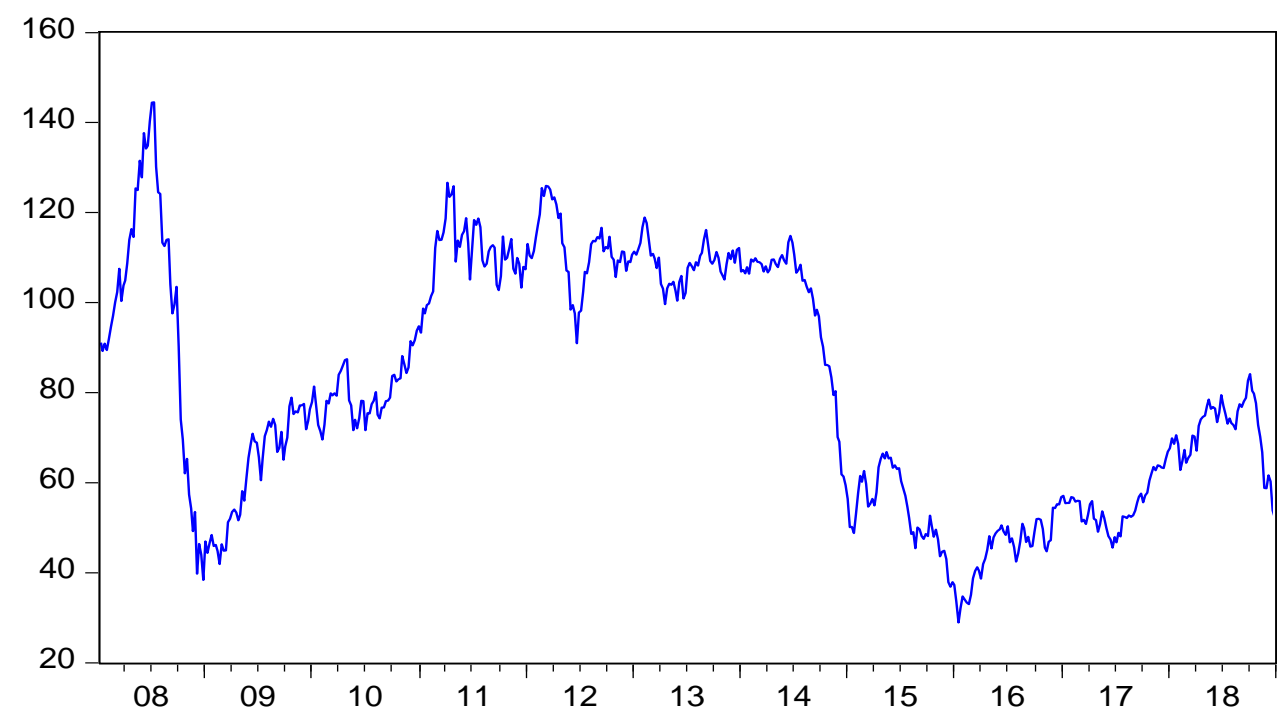

Figure 6. Oil prices trend. Graphic representation

Source: author's computation

The Oil prices trend passes in several fluctuation in this period. Between 2008 and 2018, the major one is the drop of the oil prices that happen between 2015 and 2016 which was due to the political reasons worldwide (Between KSA and IRAN). The oil prices fluctuations are not only due to demanded supply like any simple product, oil prices fluctuated for many other several reasons (political, price of gold, renewable energies). A complete module can be designed for this reason, but its not our scope in this paper. We are using the Brent prices as one of the major variables that affect the market return in KSA. And if we analyze the above two graphs, we can notice that the two charts are following the same trend. 
Below, Figure 7 presents the graph related to the adjusted series of the oil prices, the D one, which studies the change between period $\mathrm{n}$ and period $\mathrm{n}-1$.

\section{Oil Prices}

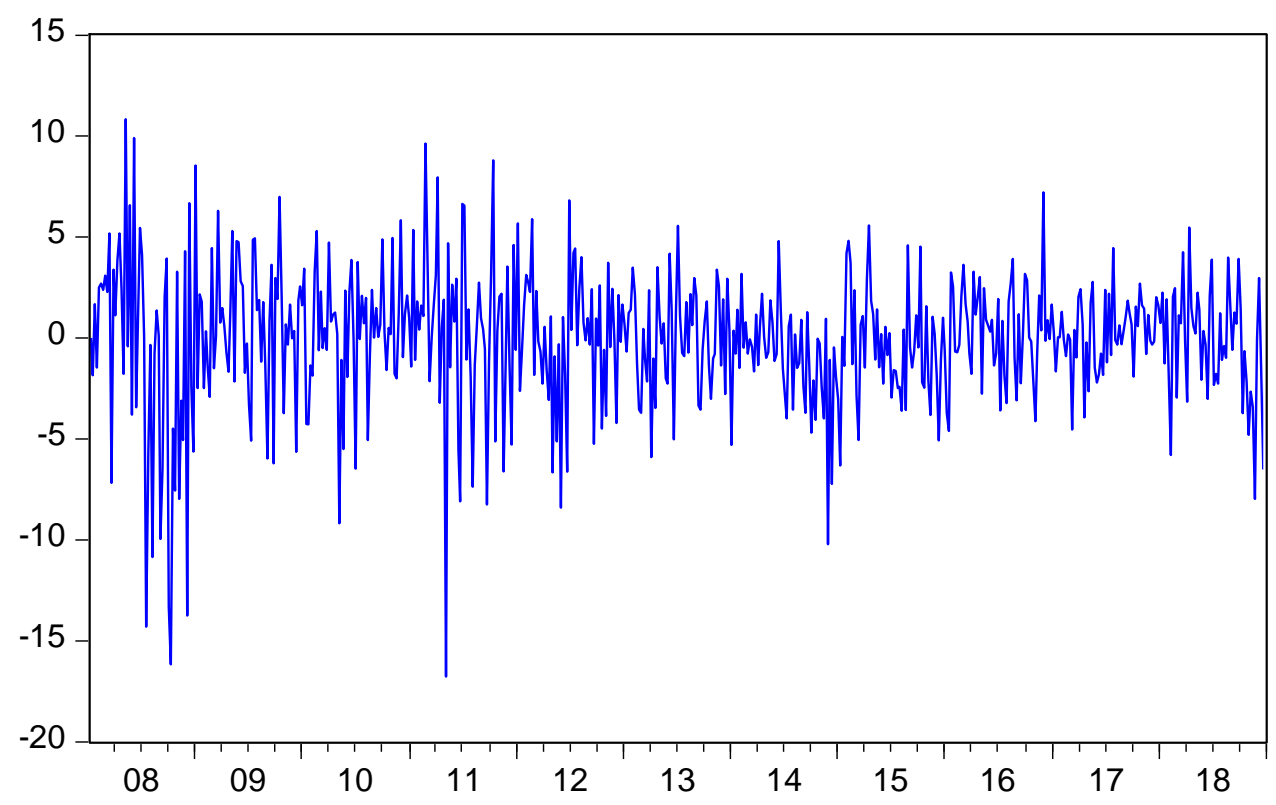

Figure 7. Adjusted series of the oil prices. Graphic representation

Source: author's computation

\section{Module}

Now we will present our module used to justify the relation between the dependent variables which is the stock market return in KSA and the other dependent variables which are: Brent oil prices (we used the stationary data after we did the transformation), exchange rate of the Rial against the USD, the interest rates, the government spending on consumer and the foreign direct investment.

As mentioned before the module will analyze the period between 2008 and 2018, and all the date used was based on weekly basis figures extracted from Bloomberg and world bank.

Stock Market Return = A + B1 Brent Oil Prices + B2 Exchange Rate + B3 Interest Rate + B4 Government Spending on Consumer + B5 Foreign Direct Investment.

The information is presented in Table 1.

The regression analysis (table 1) aims to study the relationship between oil prices, exchange rate, interest rate, government spending, foreign direct investment and their impact on stock returns in KSA.

Since the adjusted $\mathrm{R}$ squared is $69.5 \%$, this means that the independent variables taken into this module justify $69.5 \%$ the fluctuations of the dependent variable. This percentage is considered acceptable since there are many other dependent variables might be added to this model (i.e.: political variables, legal variables related to ownership, etc.) model explains the fluctuations of the dependent variable.

Adjusted R squared is used instead of the R Squared, is to avoid the inflation of the Squared due to the intersection of the probability of the coefficients. 
The non-explained variables (Remaining 31.5\%) is due to sampling error, variables not considered in our module or outliers within the data used.

Using the F test we can test the reliability of the module used, where the null hypothesis H0 will be that all coefficients is equal to zero, module not reliable, while $\mathrm{H} 1$ test that at least one of the coefficients does not equal to zero, module is reliable. Since the F test $=0.00000$ which is less than 0.5 , this means that the module is reliable.

Table 1. Market return regression analysis

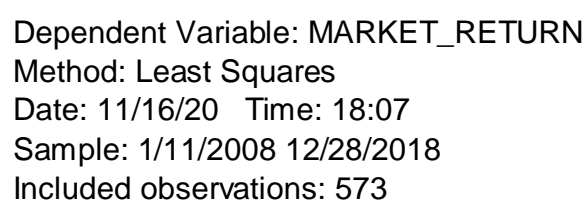

\begin{tabular}{|c|c|c|c|c|}
\hline Variable & Coefficient & Std. Error & t-Statistic & Prob. \\
\hline C & -184985.0 & 86533.12 & -2.137737 & 0.0330 \\
\hline OIL_PRICES__BRENT_ & 49.84597 & 1.638518 & 30.42137 & 0.0000 \\
\hline EXC̄HANGE__RATE_SARUSD_ & 665030.9 & 324420.5 & 2.049904 & 0.0048 \\
\hline INTEREST_RATE_LIBIOR_ & 747.4926 & 77.17919 & 9.685158 & 0.0000 \\
\hline INTEREST RATE SAIBOR & 10.29958 & 72.62525 & 0.141818 & 0.8873 \\
\hline $\begin{array}{l}\text { FOREIGN_DIRECT_INVESTMEN } \\
\text { GENERAL_GOVERNMENT_FINA }\end{array}$ & 75.63902 & 15.13878 & 4.996374 & 0.0000 \\
\hline $\mathrm{L}$ & 437.0320 & 15.92192 & 27.44844 & 0.0000 \\
\hline R-squared & 0.698399 & \multicolumn{2}{|c|}{ Mean dependent var } & 7334.480 \\
\hline Adjusted R-squared & 0.695202 & \multicolumn{2}{|c|}{ S.D. dependent var } & 1366.384 \\
\hline S.E. of regression & 754.3600 & \multicolumn{2}{|c|}{ Akaike info criterion } & 16.10176 \\
\hline Sum squared resid & $3.22 \mathrm{E}+08$ & \multicolumn{2}{|c|}{ Schwarz criterion } & 16.15491 \\
\hline Log likelihood & -4606.154 & \multicolumn{2}{|c|}{ Hannan-Quinn criter. } & 16.12249 \\
\hline F-statistic & 218.4423 & \multicolumn{2}{|c|}{ Durbin-Watson stat } & 0.188478 \\
\hline Prob(F-statistic) & 0.000000 & & & \\
\hline
\end{tabular}

Source: author's computation

In order to test whether the variables are reliable we used $\mathrm{T}$ test. The $\mathrm{H} 0$ will be that coefficient of the variable equal to zero, while $\mathrm{H} 1$ that the coefficient of the variables does not equal to zero.

Since the $\mathrm{T}$ test of all the dependent variables is less than 0.05 , then $\mathrm{H} 0$ is rejected and $\mathrm{H} 1$ is accepted. This means that all the variables chosen in the module are reliable.

Also, we divide the Coefficient over the standard error we maintain the T-Test, thus it can be noted that:

- Oil Prices: $49.8 / 1.63=30.17$

- Exchange Rate: $665030 / 324420=2.04$

- Interest Rate Libor: $75 / 15=4.99$

- Foreign Direct Investment: 75.16/15.9= 7.72

- Government Spending: 437 / $15=29.13$

In addition to the above the sign of each coefficient ties for the direction of the relationship between the dependent variable and the independent variables. Based on above we reach a conclusion that there is a positive relationship between the stock market return and all the dependent variables used in this module: oil price, interest rate, government spending, and foreign direct Investment, which means when the Brent oil prices goes up the market return 
will increase, and when the Brent oil prices goes down the market return will decrease. Same applied for the other variables that have positive coefficient. It is worth mentioning that the direction of a relationship might change if we change the period of the data we used. Since most of these variables is related to the monetary policy and fiscal policy applied by the government. But for the period we cover, we can conclude that there is a positive relationship between the depend variable and the independent variables.

In conclusion, this means that there is a significant relationship between oil prices, interest rates, government spending, foreign direct investment, and stock returns since they scored a T-Test lower than 2. As for exchange rates it scored a T-Test above than 2 meaning that there is no relationship between exchange rates and stock returns.

\section{CONCLUSIONS}

The VAR econometric method estimators were tested and applied to the core sample of our research, Arab countries, in the general and competitive models of economic growth and stock market creation. Details of the main findings and political consequences for both of these classes are now more extensively addressed. In terms of capital exchange liquidity and economic reform in Arab countries, the outcomes of the competitive development model focused on GMM assessors are very close to those obtained with OLS.

The key results showed that the contemporary and postponed impacts on economic development in either capital market liquidity, as measured by turnover or economic change, as measured by the institutional efficiency index. The relationship predictor (investment / Turnover ratio) was seen for the Arab countries to have an important result from the robustness measure. Implementing the strategy of gross capital expenditure expansion and the turnover partnership will lead to a positive impact on the connection between country expenditure and stock market liquidity during the competitive growth model.

Arab bond markets are under-driven and play a minor position in corporate finance and real economic sector, because of negligible variables in stock-market production to justify economic growth. In the face of Arab fund movements and diversification, Arab capital markets are comparatively close to international foreign buyers, badly controlled, and separate constraints remain.

The task for Arab Governments is to offer foreign investors complete access to their portfolio capital inflows and improve liquidity, thus prompting Arab economy expansion, and lifting current financial restrictions. Another significant policy influence is that an institutional and economic climate for Arab regimes should be established as a major requirement for economic development in order to regulate corruption and to draw foreign financial investment effectively.

An economic transition that would effectively supplement the financial services offered by the banking sector in the area with adequate regulations protecting the local and international investors will help global capital find its path to profitable ventures in the area and the growth of equity markets.

Capital markets liquidity had an important influence and association with economic growth in both procedures. Clearly in Corporate Finance, equity markets are highly significant, and are recognised by all indices of the scale of stock markets, operation, and liquidity as well as well-developed markets. 
This is consistent with the initial hypothesis that a well-functioning stock market may influences economic performance in a business economy by growing savings, productive capital distribution and optimizing the use of established capital.

GCC economies have an institutional efficiency index on average which is not significant. The index may be clarified by the fact that the duration of this analysis was largely prosperous and economic development in these countries already represents the impact of the business cycle.

The key effects on growth factors showed on average some indications and significances of variants due to variations in the calculation methods and the study community of the three classes of Arab countries. Investment and inflation in both alternate prediction approaches have shown strong impacts on economic development.

Furthermore, the oil impact was optimistic and important, confirming oil's superior economic growth weight and impact. In the oil export countries and in the non-oil countries, the income from oil exports has led to developing healthcare and helping to fund infrastructure and human resource projects. Implementing an economic stability program specifically intended to produce high investing levels and to reduce inflation rates to healthy levels will fuel Arab economic development.

That is, it follows the principle of economics that higher savings and lower inflation rates contribute to higher development. As the complete sample and separately for each community of the Arab countries, it was identified that the convergence income impact was important and typical across countries. It is apparent from this convergence that the per capita GDP growth rate has a negative correlation with the delayed original per capita GDP level after controlling other macroeconomic variables which may impact economic growth. For the three classes of Arab nations, the principal outcome of the time series and the individual nation methodology is primarily in line with the panel findings of our expert methodological research.

\section{RESEARCH CONTRIBUTIONS}

Further analysis will be useful for the countries of Arab countries to include in the current theoretical structure, competitive economic growth and stock market creation, the consideration of further components, such as private-sector banking credit, the market interest rate and convergence of stock markets.

The theoretical paper highlighted the position of banking credit and market interest rates as not the subject of this analysis in the financing and investment activities. The convergence of Arab capital markets at regional or global level is seen by the literature as an asset in the future and usually gives local and foreign investment diversification advantages.

More Arab collaboration on stock market growth and economic change is nevertheless required to improve investor confidence and economic stability. In the background of Arab countries, another significant field of potential study is to recognize the causal ties between the growth of the financial market, privatization and expenditure on the one hand and stock market development and petroleum revenues on the other.

This might create initial causal connections between actual economic practices and the Arab financial markets. Creation of the capital exchange may encourage privatization and the 
acquisition of additional debt financing. In this analysis, the influence of investment and oil was viewed as control variables for the single trigger of the development of the stock market to economic growth. An econometric-sensitive comparison was not, if ever, applied in such countries between Arab equity markets with separate financial regimes. A modern field of study to evaluate competitive growth and stock market trends along with growth determinants for control of variables is given by similar and different elements of estimate results for various classes of countries.

The various impacts on bursary trends between East Asia Pacific and the G7 economies for macroeconomic variables will be essential to re-examine. An effective study of this partnership by using various economic growth levels and stock-market development was rendered by a comparative analysis of the Arab nations with Eastern Asia-Pacific countries and $\mathrm{G} 7$ economies.

Since there are few studies on Arab financial markets, most of these studies explored the impact of financial progress on economic growth via the variables in the banking sector, such as liquid liabilities and large availability of cash.

The area of inquiry, however, remains quite flexible, subject to the numerous economic conditions on the Arab and global capital markets and ongoing regulatory and structural reform initiatives in the country. This research is the first systematic test of the impact on economic development of the Arab capital markets and economic change. The research analyzed current econometric techniques in the consistent panel data set for the three classes of countries during the 2008-2018 periods using different econometric methods.

\section{STUDY LIMITATIONS}

Some limits emerge from the contrasting opinions on the connection between stock market development and economic growth in this report. The notion of bond production promoting economic growth, on the one side, is unclear.

In the other side, theory offers no unique paradigm for scientific analysis to analyze this association. Economists and researchers have used numerous econometric methods and techniques in this regard to connect future bond production with economic growth.

Specifically, in terms of stock market development and the choice of growth determinants needed to track the relationship between stock market development and economic growth, there is no detailed theoretical structure. Furthermore, a substantial amount of observational experiments are prone to model defects and are often susceptible to data coverage for countries and ages.

The second restriction is that the details included in this analysis was lacking in Arab capital markets. Provided that analytical research was usually carried out on the data available on the Arab stock markets and economic development, annual scale and operation data on the Arab stock markets and the key determinants of economic growth could hardly be found on a quarterly or longer basis.

The lack of data restricts the capacity of us to apply sophisticated co-integration methods study to the ties between stock market creation and Arab countries ' economic growth. The third weakness is that in the previous research, there is no typical intervention on the growth 
of the stock market, that is to say each empirical analysis and theoretical model based on one aspect of stock market scale, operation or liquidity as channels to real economic activities.

The methods used in literature undermine the principle and the availability of evidence. The key constraint for the analysis is then how to calculate the growth of the stock market. This analysis considered and calculated four acts of stock market growth. However, these shortcomings have made the application for the Arab countries with sophisticated econometric techniques on consistent panel data sets.

\section{REFERENCES}

Ajmi, A., Montasser, G., Hammoudeh, S., \& Nguyen, D. (2014). Oil prices and MENA stock markets: New evidence from nonlinear and asymmetric causalities during and after the crisis period. Working Paper Series, IPAG Business School.

Al-Assaf, G. (2014). Testing for asymmetric cointegration relationship between banking sector development and trade openness: Evidence from Jordan. Dirasat: Administrative Sciences, 41(2).

Al-Majali, A., \& Al-Assaf, G. (2014). Long-run and short-run relationship between stock market index and main macroeconomic variables performance in Jordan. European Scientific Journal, 10(10), 156-171.

Al-Qudah, A. (2014). The impact of oil price shocks on Amman stock exchange real returns. International Journal of Business and Social Science, 5(12), 224-235

Dhaoui, A., \& Khraief, N. (2014). Empirical linkage between oil price and stock market returns and volatility: Evidence from international developed markets. Economics, 20(2).

Diaz, E., Molero, J., \& Gracia, F. (2016). Oil price volatility and stock returns in the G7 Economics. Energy Economics, 54(4), 417-430.

Dogan, F., Silahli, B., Cifter, A., \& Akay, G. (2016). The effects of oil prices on stock returns in MENA countries: A firm-level date analysis. Retrieved from http://www.dohainstitute.edu.qa/MEEA2016/downloads/fadime\%20dogan Final.pdf

Gomes, M., \& Chaibi, A. (2014). Volatility spillovers between oil prices and stock returns: A focus on frontier market. The Journal of applied Business Research, 30(2), 509-526.

Masih, R., Perters, S., \& Mello, L. (2010). Oil price volatility and stock price fluctuations in an http://ijfr.sciedupress.com International Journal of Financial Research

Moghadam, H. (2010). Asymmetric effect of oil price shocks on stock markets. Retrieved from http://www.ssm.com/abstract=2787019

Momani, G., \& Alsharari, M. (2012). Impact of economic factors on the stock prices at Amman stock market (1992 - 2010). International Journal of Economics and Finance, 4(1), 151-159.

Ramos, S., \& Velga, H. (2010). Asymmetric effects of oil price fluctuations in international stock markets. Working papers. Universidad Carlos III de Madrid.

Zhu, H., Su, X., Guo, Y., \& Ren, Y. (2016). The asymmetric effects of oil price shocks on the Chinese stock market: Evidence from a quantive impulse perponse perspective. Sustainability, 8(766), 119. 